
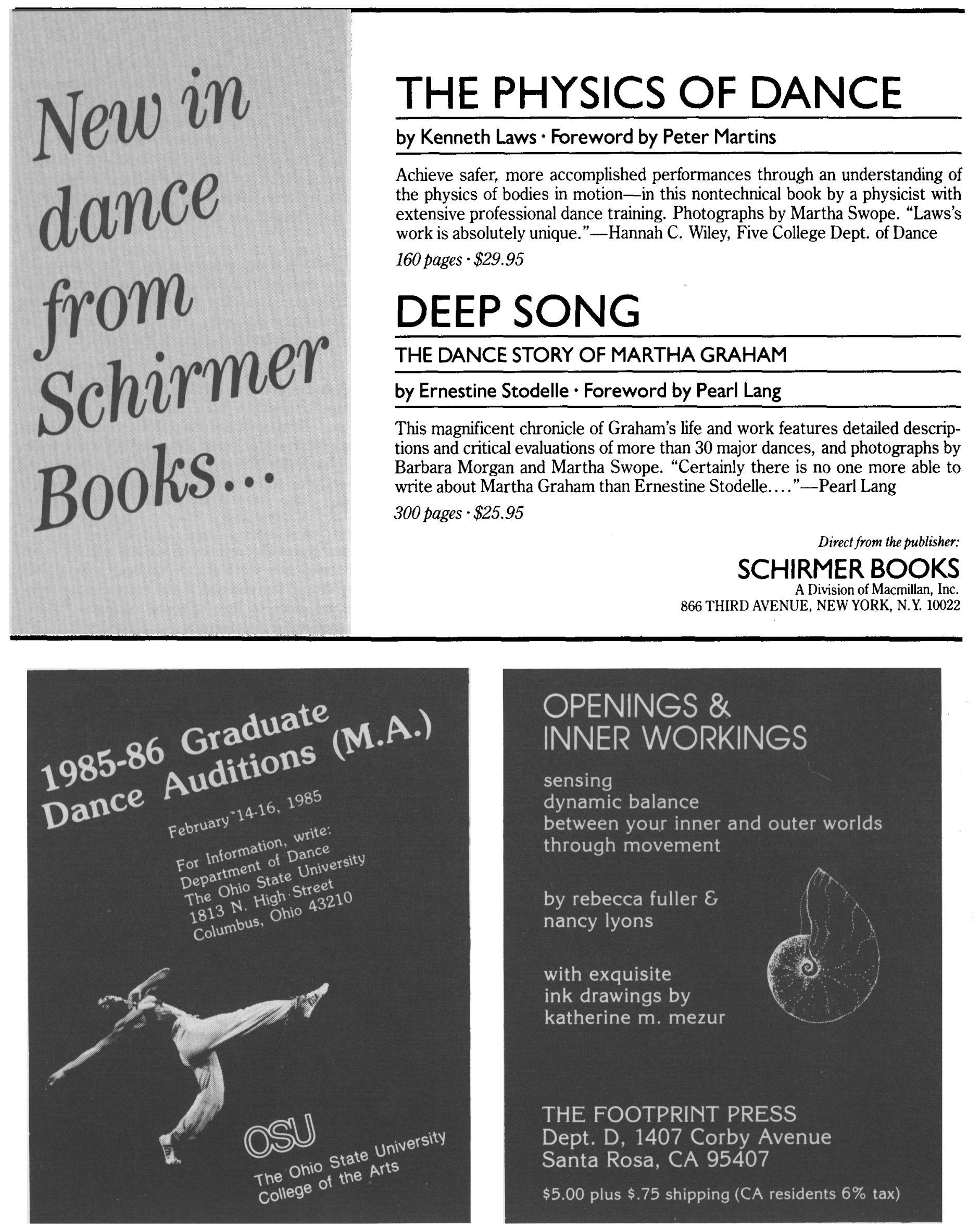

OPENINGS \& INNER WORKINGS

sensing

dynamic balance

between your inner and outer worlds

through movement

by rebecca fuller $\mathcal{E}$

nancy lyons

with exquisite

ink drawings by

katherine $\mathrm{m}$. mezur

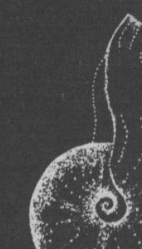

THE FOOTPRINT PRESS

Dept. D, 1407 Corby Avenue

Santa Rosa, CA 95407

$\$ 5.00$ plus $\$ .75$ shipping (CA residents $6 \%$ tax) 

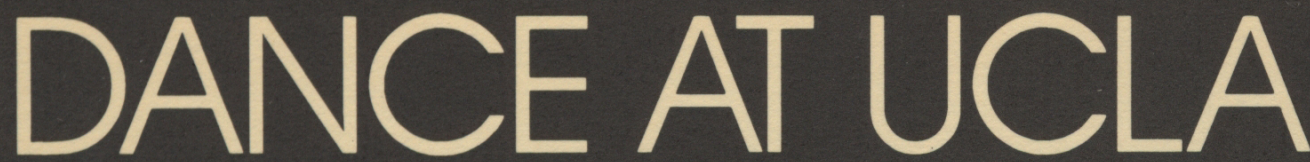

\section{Undergraduate Program}

BA in modern dance with emphasis on choreography. Classes in technique, composition, history, music, lighting, design, kinesiology, notation, improvisation, ballet, ethnic dance and education.

\section{Graduate Program}

MA specializations include choreography, performance, ethnology, education, therapy.

\section{Admissions}

Undergraduate: Application filing period for Fall Quarter 1985 is November 1, 1984 through February 28, 1985. No auditions for freshmen. Auditions for transfer students in New York City on February 16 and at UCLA on March 16 (or by tape).

Graduate: Auditions at UCLA on February 9 \& 10 and in New York City on February 16.

For Information \& Applications Contact:

UCLA Department of Dance

Room D

Los Angeles, California 90024

(213) 825-3951

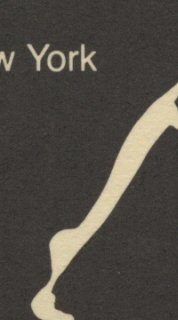

\section{政}

